\title{
Spatiotemporal distribution of nitrogen dioxide within and around a large-scale wind farm - a numerical case study
}

\author{
Jingyue Mo ${ }^{1,2}$, Tao Huang ${ }^{1}$, Xiaodong Zhang ${ }^{1}$, Yuan Zhao ${ }^{1}$, Xiao Liu ${ }^{2}$, Jixiang $\mathbf{L i}^{1,2}$, Hong Gao ${ }^{1}$, and Jianmin Ma ${ }^{1,3,4}$ \\ ${ }^{1}$ Key Laboratory for Environmental Pollution Prediction and Control, Gansu Province, \\ College of Earth and Environmental Sciences, Lanzhou University, Lanzhou, China \\ ${ }^{2}$ College of Atmospheric Sciences, Lanzhou University, Lanzhou, China \\ ${ }^{3}$ Laboratory for Earth Surface Processes, College of Urban and Environmental Sciences, Peking University, Beijing, China \\ ${ }^{4}$ CAS Center for Excellence in Tibetan Plateau Earth Sciences, Chinese Academy of Sciences, Beijing, China
}

Correspondence to: Jianmin Ma (jianminma@1zu.edu.cn) and Tao Huang (huangt@1zu.edu.cn)

Received: 24 July 2017 - Discussion started: 14 August 2017

Revised: 24 October 2017 - Accepted: 29 October 2017 - Published: 1 December 2017

\begin{abstract}
As a renewable and clean energy source, wind power has become the most rapidly growing energy resource worldwide in the past decades. Wind power has been thought not to exert any negative impacts on the environment. However, since a wind farm can alter the local meteorological conditions and increase the surface roughness lengths, it may affect air pollutants passing through and over the wind farm after released from their sources and delivered to the wind farm. In the present study, we simulated the nitrogen dioxide $\left(\mathrm{NO}_{2}\right)$ air concentration within and around the world's largest wind farm (Jiuquan wind farm in Gansu Province, China) using a coupled meteorology and atmospheric chemistry model WRF-Chem. The results revealed an "edge effect", which featured higher $\mathrm{NO}_{2}$ levels at the immediate upwind and border region of the wind farm and lower $\mathrm{NO}_{2}$ concentration within the wind farm and the immediate downwind transition area of the wind farm. A surface roughness length scheme and a wind turbine drag force scheme were employed to parameterize the wind farm in this model investigation. Modeling results show that both parameterization schemes yield higher concentration in the immediate upstream of the wind farm and lower concentration within the wind farm compared to the case without the wind farm. We infer this edge effect and the spatial distribution of air pollutants to be the result of the internal boundary layer induced by the changes in wind speed and turbulence intensity driven by the rotation of the wind turbine rotor blades and the enhancement of surface roughness length over the wind farm. The step change in the roughness length from the smooth to
\end{abstract}

rough surfaces (overshooting) in the upstream of the wind farm decelerates the atmospheric transport of air pollutants, leading to their accumulation. The rough to the smooth surface (undershooting) in the downstream of the wind farm accelerates the atmospheric transport of air pollutants, resulting in lower concentration level.

\section{Introduction}

Wind power has been the fastest-growing energy source and one of the most rapidly expanding industries around the globe. To achieve sustainable development, establish an "environment-friendly society", and reduce emissions of $\mathrm{CO}_{2}$ and other air pollutants, considerable efforts have been made in China to develop and expand wind power generation in the past decade. China's wind power has increased $100 \%$ from 2006 to 2010. By 2015, the total installed capacity of wind power became the largest globally with the capacity of $140 \mathrm{GW}$ (GWEC, 2016). It is projected that wind power capacity in the nation will reach $200 \mathrm{GW}$ by $2020,400 \mathrm{GW}$ by 2030 , and $1000 \mathrm{GW}$ by 2050 . In 2016 , the wind power capacity accounted for $4 \%$ of total national electricity consumption. It is expected that wind power will become one of five main power sources and meet $17 \%$ of the total electricity demand in China in the mid-21st century (IEA, 2011).

Extensive field and modeling studies have demonstrated that a relatively large-scale wind farm could alter the local meteorological and climate conditions. From a dynamic per- 
spective, a large-scale wind farm can be approximately regarded as a sink of kinetic energy (KE) and source of turbulent kinetic energy (TKE). Turbulence generated by wind turbine rotors could create eddies that can enhance vertical mixing of momentum, reducing the wind speed at the turbine hub height level (Baidya et al., 2004; Baidya, 2011; Barrie and Kirk-Davidoff, 2010). The wind farm-induced turbulence can also alter the vertical mixing which can markedly affect the vertical distribution of temperature and humidity (Baidya et al., 2004; Baidya, 2011). Coupled atmosphereocean climate model has predicted that the global distribution of wind farms could increase air temperature by up to $1{ }^{\circ} \mathrm{C}$ in inland wind farms and cool down temperature near the ground surface by $1^{\circ} \mathrm{C}$ in offshore wind farms (Keith et al., 2004). Ocean-atmosphere heat fluxes would increase in response to increasing turbulence produced by wind farms (Barrie and Kirk-Davidoff, 2010). Nevertheless, although the effects of wind farms on meteorology have been observed and simulated, overall the net impact of wind power on global surface temperatures may be overlooked (Wang and Prinn, 2010). Satellite remote sensing and model simulations confirmed that the degree of variations in the surface temperature altered by large-scale wind farms were not significant compared to the benefit from wind power in the emission reduction of $\mathrm{CO}_{2}$ and other greenhouse gases (Barrie and KirkDavidoff, 2010; Keith et al., 2004; Baidya, 2011; Zhou et al., 2012).

As a clean energy source, a wind farm does not release any harmful chemicals into the air and hence has not received particular attention in the scientific community compared to its negative environmental impacts on wildlife, its noise and visual impact (Saidur et al., 2011; Magoha, 2002; Loss et al., 2013), and meteorological and climate conditions. Wind farms could alter the underlying surface characteristics and disturb winds and turbulence near and within the wind farms by enhancing the surface roughness length through the layout of wind turbines and the spinning condition of the wind turbine rotors. These changes mostly occur near the surface or the atmospheric boundary layer where the levels of air pollutants are highest. As a result, the wind power operation might affect the atmospheric transport and diffusion of an air pollutant released from its industrial and mobile sources near the wind farm. Furthermore, considering the fast expansion of wind energy industry in the past and future, a question may arise: would the increasing number of wind farms perturb local, regional, and national air pollution forecasting?

The effect of the wind farm on air pollution depends on several factors, including the source locations, proximity and strength, wind speed and direction, and wind turbine size and layout in the wind farm. It is not straightforward to measure the perturbation of an air pollutant induced by a wind farm. As an alternative, the present study made use of a coupled weather forecast and atmospheric chemistry model to simulate the air pollution within and around a large-scale wind farm subject to a typical atmospheric transport event of air pollutants emitted from a point source near the wind farm, aiming to (1) assess and quantify the temporal evolution and spatial distribution of the air pollutant within and around the wind farm, (2) evaluate the wind and turbulent fields that drive the spatiotemporal variation of the air pollutant over the wind farm, and (3) identify primary characteristics of the air pollutant in the wind farm under a specific mesoscale circulation over the wind farm. Results are reported below.

\section{Materials and methods}

\subsection{Locations of wind farm and major emission source}

The location of the selected wind farm in this study is illustrated in Fig. 1. This wind farm extends from Yumen $\left(40^{\circ} 16^{\prime} \mathrm{N}, 97^{\circ} 02^{\prime} \mathrm{E}\right)$ to Guazhou $\left(40^{\circ} 31^{\prime} \mathrm{N}, 95^{\circ} 42^{\prime} \mathrm{E}\right)$ in Jiuquan, located in the west end of the Hexi Corridor, Gansu Province, northwestern China (Fig. 1a). Given its huge wind energy resources, Jiuquan region has been termed "the Land Three Gorges" (the Three Gorges being the largest hydroelectric power station in the world). The Jiuquan wind farm, which consists of Yumen wind farm (YWF) and Guazhou wind farm (GWF), has been ranked as the largest wind farm in the world (Fig. 1b). The total cumulative wind power energy was about $12 \mathrm{GW}$ in 2015 and is projected to reach $13.6 \mathrm{GW}$ by 2020 . The wind turbine hub height in the YWF and GWF ranges from 70 to $90 \mathrm{~m}$ and rotor diameter ranges from 83 to $113 \mathrm{~m}$ (CCER, 2015). This large-scale wind farm covers an area about $2000 \mathrm{~km}^{2}$. The underlying surfaces over the YWF and GWF are almost entirely covered by the Gobi Desert and bare lands with only few residential areas. The terrain height in the wind farm ranges from 1.2 to $2 \mathrm{~km}$ above the sea level. Both YWF and GWF are located closely in the suburb of Jiuquan and Jiayuguan, the two largest cities in the Hexi Corridor. The largest emission source of air pollutants proximate to the Jiuquan wind farm (YWF and GWF) is the Jiuquan Iron \& Steel Group Co., Ltd. (JISCO), located in Jiayuguan City $\left(39^{\circ} 48^{\prime} \mathrm{N}, 98^{\circ} 18^{\prime} \mathrm{E}\right)$, about $110 \mathrm{~km}$ southeast of the YWF (Fig. 1b). This company is ranked as the largest iron and steel complexes in northwestern China and one of the top 50 iron and steel companies in the world.

\subsection{WRF-Chem model setup and configuration}

We applied WRF-Chem model v3.7 (http://www2.mmm. ucar.edu/wrf/users/wrfv3.7/wrf_model.html) to simulate the meteorological field and atmospheric chemistry. The WRFChem (the Weather Research and Forecasting model coupled with Chemistry) is a new-generation air quality model with its air quality component (Chem) and meteorological component (WRF) being fully coupled in an "online" approach (Grell et al., 2005). The physical options in WRFChem v3.7 include the Lin microphysics scheme (Lin et al., 1983), the Rapid Radiative Transfer Model (RRTM) longwave radiation scheme (Mlawer et al., 1997), Goddard short- 

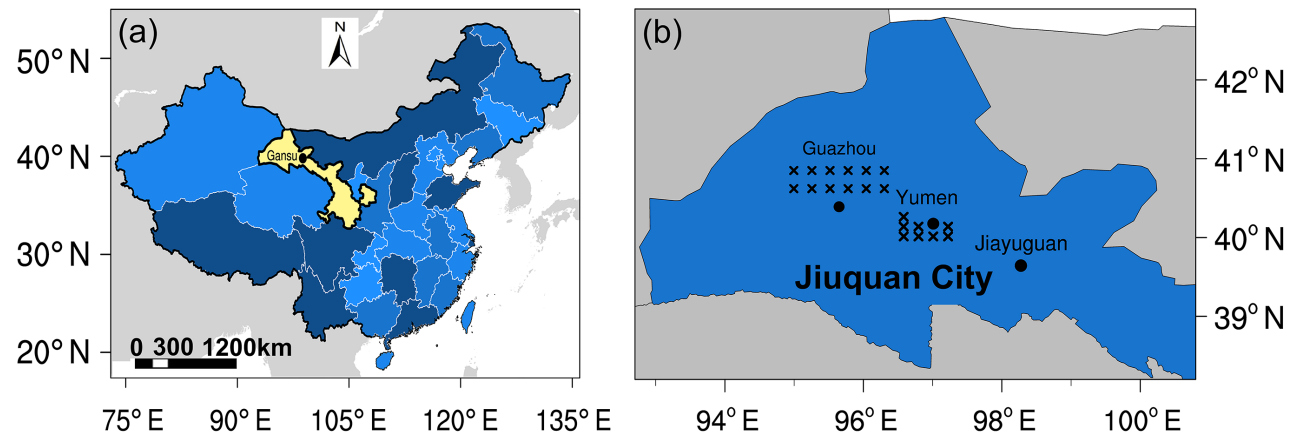

Figure 1. Location of Gansu province (shaded yellow area, a) and wind farms in Jiuquan City (b). Black cross represents YWF and GWF and black dots show Yumen City $\left(40^{\circ} 16^{\prime} \mathrm{N}, 97^{\circ} 02^{\prime} \mathrm{E}\right)$, Guazhou $\left(40^{\circ} 31^{\prime} \mathrm{N}, 95^{\circ} 42^{\prime} \mathrm{E}\right)$, and Jiayuguan City $\left(39^{\circ} 48^{\prime} \mathrm{N}, 98^{\circ} 18^{\prime} \mathrm{E}\right)$, where JISCO is located.

wave scheme (Kim and Wang, 2011), revised MM5 M-O surface layer scheme (Beljaars, 1994; Chen and Dudhia, 2001), YSU (Yonsei University) boundary layer scheme (Hong et al., 2006), new Grell cumulus scheme (Grell and Devenyi, 2002), and Unified Noah land surface model (Chen and Dudhia, 2001). The chemical options include Madronich TUV, FTUV, and Fast-J (Fast et al., 2006) photolysis scheme, modified CB05 gas-phase chemistry scheme with updated chlorine chemistry (Yarwood et al., 2005), several photo chemical mechanisms by RADM2 (Middleton et al., 1990), CBMZ, SAPRC, MEGAN biogenic emission scheme (Guenther et al., 2012), and three aerosol modules, MADE/SORGAM, MOSAIC, and a simple aerosol module from GOCART.

We used the anthropogenic emissions from HTAP_V2 (Task Force on Hemispheric Transport of Air Pollution, 2012). This emission inventory consists of the gridded emission data and grid maps of $\mathrm{CH}_{4}, \mathrm{CO}, \mathrm{SO}_{2}, \mathrm{NO}_{x}$, NMVOC, $\mathrm{NH}_{3}, \mathrm{PM}_{10}, \mathrm{PM}_{2.5}, \mathrm{BC}$, and $\mathrm{OC}$ at a $0.1^{\circ}$ latitude $\times 0.1^{\circ}$ longitude resolution. The global grid maps are a joint effort from the USEPA, the MICS-Asia group, EMEP/TNO, and the REAS and the EDGAR groups. The bio-emission calculated by MEGAN V2.1 has a spatial resolution of $1 \mathrm{~km}$ (Model of Emissions of Gases and Aerosols from Nature, 2011). The FNL reanalysis data with $0.25^{\circ} \times 0.25^{\circ}$ (latitude $\times$ longitude) provided by the National Centers for Environmental Prediction/National Center for Atmospheric Research (NCEP/NCAR) were used as initial and lateral boundary conditions.

Three nested domains at $10,3.3$, and $1.1 \mathrm{~km}$ resolutions were set up. The first domain (d01) with $10 \mathrm{~km}$ spacing and an area of $850 \mathrm{~km} \times 750 \mathrm{~km}$ covers Gansu Province and part of Xinjiang Province. The second domain (d02) with $3.3 \mathrm{~km}$ spacing and an area of $413 \mathrm{~km} \times 253 \mathrm{~km}$ covers Guazhou and Yumen wind farm. The third domain (d03) with $1.1 \mathrm{~km}$ spacing and an area of $124 \mathrm{~km} \times 124 \mathrm{~km}$ covers Yumen wind farm only. The spatial configurations of these three model domains are illustrated in Fig. 2. The fine domain lateral boundary conditions for the meteorological variables and air pollutants are interpolated from the coarse domain prediction. Two-way nesting is then optionally achieved by having the fine grid solution replace the coarse grid solution for those grid nodes that lie within the fine nest domain. The model has 28 eta levels with the top of $100 \mathrm{hPa}$. The vertical resolution is much denser near the surface with 13 eta levels in the lowest $1 \mathrm{~km}$ of the model atmosphere (about 10, 40, 75, 100, $130 \mathrm{~m}$, etc.) so as to achieve more accurate simulations of meteorology and atmospheric chemistry in the planetary boundary layer (PBL).

\subsection{Wind farm parameterization scheme}

Two wind farm parameterization schemes were adopted to parameterize winds and turbulence fields forced by the wind turbines across the wind farm. The first one is the surface roughness length parameterization. In this scheme, a wind farm can be seen to increase underlying surface obstacles which reduce the wind speed in the hub height, featured by the increase in the aerodynamic roughness length (Baiyda et al., 2004; Keith et al., 2004; Oerlemans et al., 2007). Some of the previous model studies were conducted by increasing the surface roughness lengths to quantify the aerodynamic effect of wind turbines on wind and turbulence profiles (Frandsen, 1992; Baidya et al., 2004; Keith et al., 2004). We adopted a similar approach to enhance the roughness lengths over the GWF and YWF. To do so, we replaced the land use types and surface roughness lengths defined by LU_INDEX and LANDUSEF variables in the geo-data of the WPS by a landuse-type scheme which takes into account typical land surface characteristics in northwestern China (Zhang and Zhao, 2015) and estimated effective roughness lengths in wind farm parameterization. In this parameterization scheme, the roughness lengths in the wind farm were calculated using the Lettau roughness length equation (Lettau, 1965):

$z_{0}=0.5 h^{*} \frac{S_{\mathrm{S}}}{S_{\mathrm{L}}}$,

where $z_{0}$ is the roughness length in meters, and $h^{*}$ is the average vertical extent of the roughness elements or effec- 


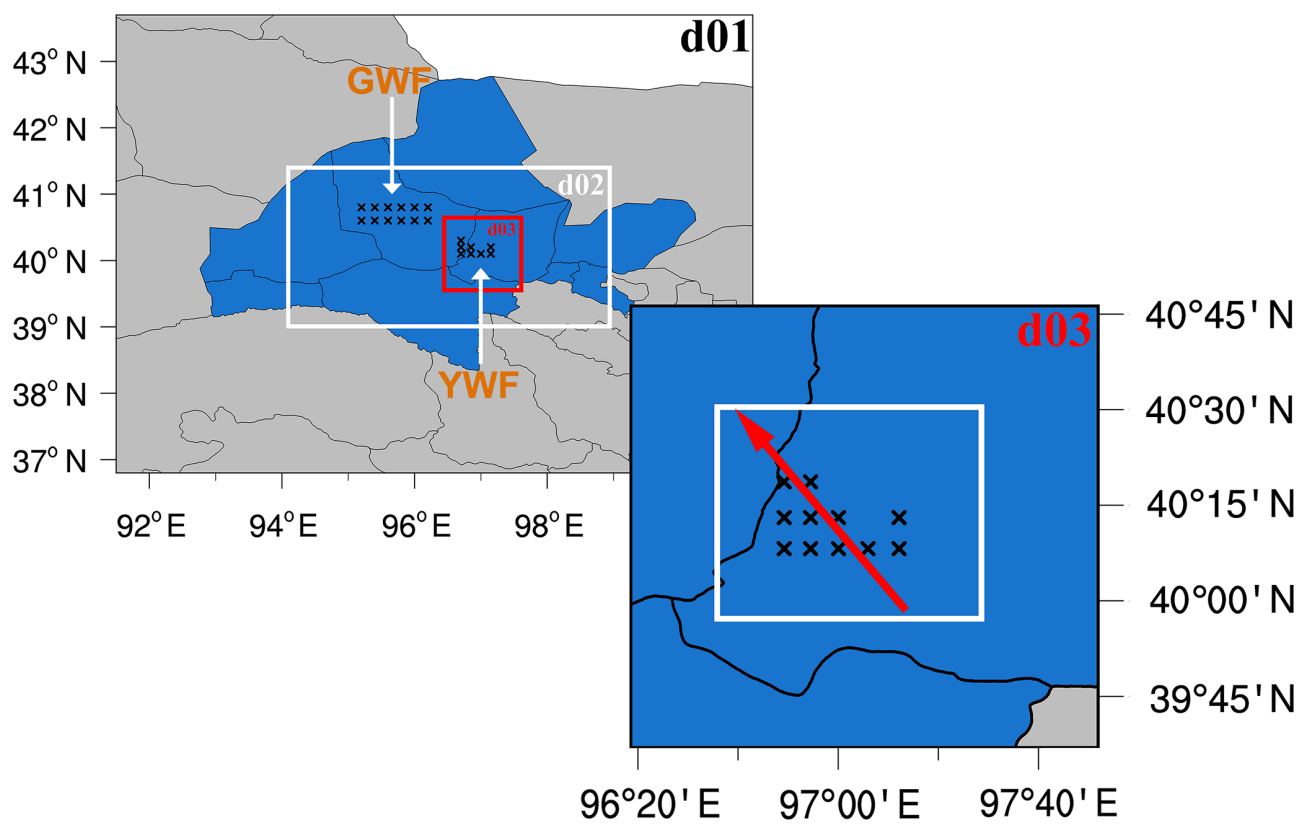

Figure 2. Nested model domains, including large domain d01 (upper-left panel), the medium size domain (d02, marked by a white box) covering Guangzhou and Yumen wind farms, and the fine domain d03 marked by the red box in upper-left panel covering Yumen wind farm only. The blue shaded area is Jiuquan City. In the d01 domain, the GWF and YWF are also indicated. These two wind farms are marked by the black cross. The lower-right panel shows the enlarged d03 area. The red arrow line indicates the transect along which the concentrations cross sections are generated (see Sect. 3). The white box represents the d03 domain covering YWF and its surrounding region.

tive obstacle height (m). In our case, $h^{*}$ is the height of the wind turbine rotor. $S_{\mathrm{S}}$ in Eq. (1) is the average silhouette area $\left(\mathrm{m}^{2}\right)$ of the average obstacle or the vertical cross-section area presented to the wind by one wind turbine, and $S_{\mathrm{L}}$ is the density of roughness element. Here $S_{\mathrm{L}}$ can be expressed as $S_{\mathrm{L}}=A / N$, where $A$ is the area of the wind farm, and $N$ is the number of wind turbines (Porté-Agel et al., 2014; Rooijmans, 2004; Frandsen, 2007). For YWF, $h^{*}$ is taken as $113 \mathrm{~m}$ (wind turbine height), $S_{\mathrm{S}}$ is taken as $10029 \mathrm{~m}^{2}$, and $S_{\mathrm{L}}$ is taken as $375000 \mathrm{~m}^{2}$. The resulted $z_{0}$ is $1.51 \mathrm{~m}$. We shall use this value as a typical roughness length to represent the underlying surface characteristics for the YWF. Knowing that bare land and Gobi Desert are dominant underlying surface of YWF and its surrounding region, the roughness length on this surface was taken as $0.01 \mathrm{~m}$ outside the wind farm in model scenario simulations except for the control model run in which this surface roughness length was applied in entire d03 model domain (see below).

The second wind farm parameterization is the wind turbine drag force scheme, developed by Fitch et al. (2012), which was extended from Blahak et al. (2010) in their modeling of the conversion of KE from atmosphere wind flow (Fitch et al., 2012; Blahak et al., 2010). This scheme has been implemented in WRF model. The turbine drag force scheme was developed subject to the Mellor-Yamada-Nakanishi-Niino (MYNN) turbulence scheme (Mellor and Yamada, 1974; Nakanishi and Niino, 2009). The Fitch scheme takes into account the effects of the wind turbines on the atmospheric flow by adding a momentum sink to the wind flow and transferring the fraction of the KE from the atmosphere into electricity and TKE. The KE is quantified by a thrust coefficient $C_{\mathrm{T}}$ which depends on the wind speed and the specification of the wind turbine. The electricity converted by KE is calculated by the power coefficient $C_{\mathrm{P}}$ with change in the wind speed and varies between 17 and $75 \%$ of $C_{\mathrm{T}}$. Both coefficients $C_{\mathrm{T}}$ and $C_{\mathrm{P}}$ can be obtained from a wind energy manufacturer. This approach assumes that the mechanical and electrical losses are negligible, so KE could be transferred to TKE, given by $C_{\mathrm{TKE}}=C_{\mathrm{T}}-C_{\mathrm{P}}$. The wind turbine drag force parameterization scheme reads

$$
\begin{aligned}
& \mathbf{F}_{\text {drag }}=\frac{1}{2} C_{\mathrm{T}}(|\boldsymbol{V}|)_{\rho}|\boldsymbol{V}| \boldsymbol{V} A, \\
& \frac{\partial \mathrm{KE}_{\mathrm{cell}}^{i j k}}{\partial t}=\frac{\partial}{\partial t} \frac{\rho_{i j k}|\boldsymbol{V}|_{i j k}^{2}}{2}\left(z_{k+1}-z_{k}\right) \Delta x \Delta y, \\
& \frac{\partial P_{i j k}}{\partial t}=\frac{\frac{1}{2} N_{t}^{i j} C_{\mathrm{P}}\left(|\boldsymbol{V}|_{i j k}\right)|\boldsymbol{V}|_{i j k}^{3} A_{i j k}}{\left(z_{k+1}-z_{k}\right)}, \\
& \frac{\partial \mathrm{TKE}_{i j k}}{\partial t}=\frac{\frac{1}{2} N_{t}^{i j} C_{\mathrm{TKE}}\left(|\boldsymbol{V}|_{i j k}\right)|\boldsymbol{V}|_{i j k}^{3} A_{i j k}}{\left(z_{k+1}-z_{k}\right)},
\end{aligned}
$$

where $\boldsymbol{V}=(u, v)$ is the horizontal velocity vector, $\rho$ is the air density, $N_{\mathrm{t}}$ is the density of wind turbines, $A=(\pi / 4) D^{2}$ is the cross-sectional rotor area (where $D$ is the diameter of the turbine rotor), $i, j, k$ are the number of grids in threedimensional space $(x, y, z), \Delta x$ and $\Delta y$ are the horizontal 
grid spacing, and $z_{k}$ is the height of vertical coordinate. In the present study, the thrust coefficient $C_{\mathrm{T}}=0.16$, the turbine hub height is $90 \mathrm{~m}$, the rotor blade diameter is $113 \mathrm{~m}$, and the nominal power of turbine is taken as $2.0 \mathrm{MW}$. These parameters are defined and implemented in the WRF files to parameterize the wind turbine profiles. It is worth noting that the wind turbine could both act as an obstacle to enhance the surface roughness and as a sink of momentum which results in the momentum loss through both surface friction and spinning wind turbine rotors. The two parameterization schemes used in the present study have, to some extent, similar physical background.

\subsection{A case study}

From 19 to 24 November 2016, a strong cold wave occurred in northern China. An anticyclone featured by a surface high-pressure system moved from western Siberia to northern China. This system forced the change in the prevailing wind direction from westerly wind to easterly and southeasterly wind across the western Hexi Corridor on the south of the anticyclone. The air quality in Jiuquan City was deteriorated during this period, characterized by the rapid increase in atmospheric levels of several criteria air pollutants sampled at the Jiuquan air monitoring station which was operated by Ministry of Environmental Protection of China (http://www.zhb.gov.cn/). Given that both YWF and GWF are located in the northwest of Jiuquan City and in the north of Jiayuguan City, where JISCO is located, heavy air pollutants from the JISCO were delivered to the two wind farms. We then performed extensive model investigations subject to the four model scenarios to assess numerically the spatiotemporal variation of air pollution in the YWF during this cold wave episode and heavy air pollution event. The target chemical selected in the present modeling investigation is $\mathrm{NO}_{2}$. Although $\mathrm{NO}_{x}$ (nitrogen oxide) as a precursor gas often receives more concern, since $\mathrm{NO}_{x}=\mathrm{NO}+\mathrm{NO}_{2}$ and $\mathrm{NO}$ (nitric oxide) can be quickly oxidized to $\mathrm{NO}_{2}$ in the ambient air, $\mathrm{NO}_{x}$ is considered to approximately be equal to $\mathrm{NO}_{2}$. In addition, $\mathrm{NO}_{2}$ is on the list of ambient air quality standards and measured routinely at air quality monitoring stations across China. These data can then be used to verify modeled air concentrations. While hourly sulfate dioxide $\left(\mathrm{SO}_{2}\right)$ concentrations were also available, its atmospheric level was lower than $\mathrm{NO}_{2}$ due to the mandatory implementation of flue-gas desulfurization at JISCO, the major emission source of air pollutants in this region.

To identify and quantify the influence of the YWF on air pollutants within and around this large-scale wind farm, we performed four model scenario runs. The first model scenario (S1) is the control run in which the YWF was not taken into consideration. Rather, we simply assigned the roughness length value of $0.01 \mathrm{~m}$ throughout the model fine domain (d03) including the YWF area. In the second model scenario (S2), the YWF was parameterized by the roughness length $z_{0}=1.51 \mathrm{~m}$ which was calculated by Eq. (1), and in the rest of the fine model grids, $z_{0}$ was taken as $0.01 \mathrm{~m}$. In the third model scenario (S3), the YWF was parameterized by the drag force approach (Fitch et al., 2012) and the distance between two wind turbines is set to $500 \mathrm{~m}$. The last model scenario (S4) also made use of the drag force approach to parameterize the YWF, but the turbine density was extended from $500 \mathrm{~m}$ to $1 \mathrm{~km}$. In the YWF, the distances between wind turbines are not uniform but range from 300 to $1000 \mathrm{~m}$ (http://cdm.ccchina. gov.cn/zyDetail.aspx $?$ newsId $=58797 \&$ TId $=169$, last access: 28 November 2017). We chose the 500 and $1000 \mathrm{~m}$ distances to examine the effects of typical distribution of wind turbines across the YWF on modeled $\mathrm{NO}_{2}$ air concentrations and the roughness lengths. The setup of the two distances also highlighted the responses of simulated air concentrations to the wind turbine density in a wind farm.

The modeled $\mathrm{NO}_{2}$ air concentrations and meteorological variables (wind speed and temperature) have been validated against available measurement data. The modeled $\mathrm{NO}_{2}$ air concentrations from the four model scenarios were compared with the monitored air concentrations from 00:00 UTC 19 November to 00:00 UTC 21 November 2016, at the Jiuquan Air Quality Monitoring Station operated by the Jiuquan Environmental Protection Agency. Overall, the model results from the four modeling scenarios agree reasonably well with the measured data, as shown in Fig. S1 and Table S1 in the Supplement. Details are presented in the Supplement.

As an operational weather forecasting model, the WRF model has been evaluated extensively. In the present study, we further compared WRF simulated winds and temperatures from the four modeling scenarios with measured data near the surface at the three routine weather stations within the fine model domain. These are Mazongshan (52323), Dunhuang (52418), and Jiuquan (52533) stations. The detailed evaluations of WRF modeled winds and temperatures are presented in the Supplement (text, Fig. S2-S4).

\section{Results}

\section{1 $\mathrm{NO}_{2}$ in YWF without wind farm parameterization}

Figure 3 shows simulated $\mathrm{NO}_{2}$ air concentrations (ppmv) superimposed by the vector winds $\left(\mathrm{m} \mathrm{s}^{-1}\right)$ at the first model vertical level $(\sim 10 \mathrm{~m})$ across the fine domain (d03) at 06:00, 12:00, and 20:00 UTC, 19 November, and 04:00 UTC, 20 November, from the model control run (model scenario 1, S1), respectively. At 06:00 UTC (local time 14:00), 19 November, weak easterly winds prevailed over most of the model domain, except in the south of the domain where northerly wind component prevailed (Fig. 3a). At this time, $\mathrm{NO}_{2}$ levels were low. At 12:00 UTC, the southeasterly winds extending from the industrial source region (JISCO) to the 
(a) level1 2016-11-19 06:00:00

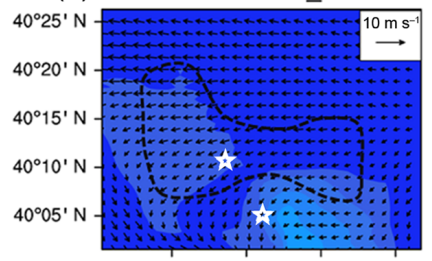

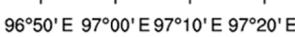
(c) level1 2016-11-19_20:00:00

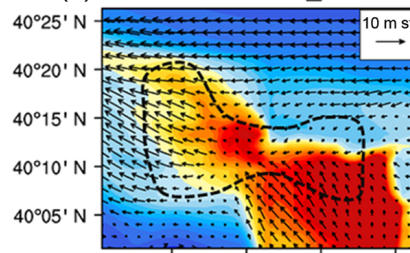

$96^{\circ} 50^{\prime}$ E $97^{\circ} 00^{\prime}$ E $97^{\circ} 10^{\prime}$ E $97^{\circ} 20^{\prime} \mathrm{E}$ $\mathrm{NO}_{2}$ (ppmv)
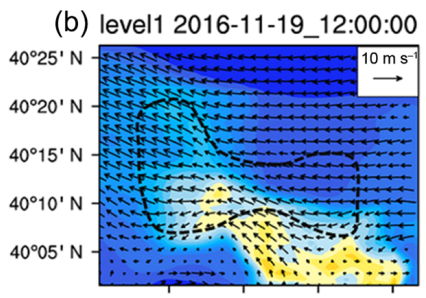

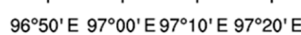
(d) level1 2016-11-20 04:00:00

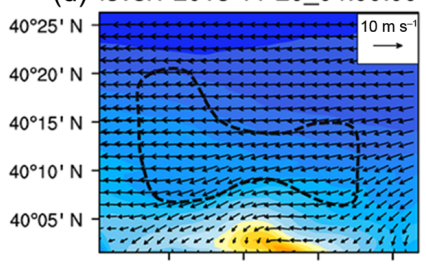

$96^{\circ} 50^{\prime}$ E $97^{\circ} 00^{\prime}$ E $97^{\circ} 10^{\prime}$ E $97^{\circ} 20^{\prime} \mathrm{E}$

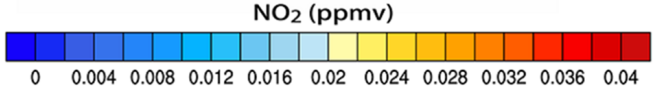

Figure 3. WRF-Chem simulated hourly $\mathrm{NO}_{2}$ air concentrations (ppmv) and vector winds at the first model level above the surface $(\sim 10 \mathrm{~m})$ at 06:00, 12:00, and 20:00 UTC, 19 November, and 04:00 UTC, 20 November, in the fine domain (d03) from the control run (S1). The YWF is encircled by the black dashed line. Two white stars highlight two model grids at which the modeled $\mathrm{NO}_{2}$ vertical profiles within and outside the YWF are compared (Figs. 11 and 13 and corresponding discussions). The one grid $(44,52)$ is located within the wind farm and the other one $(50,48)$ is located outside the YWF. The magnitude of reference wind speed at $10 \mathrm{~m} \mathrm{~s}^{-1}$ is shown in the upper-right panel.

YWF started to build up, which delivered $\mathrm{NO}_{2}$ from JISCO region to YWF (Fig. 3b). This southeasterly wind regime became stronger at 20:00 UTC, enhancing the atmospheric transport of $\mathrm{NO}_{2}$ to the YWF, characterized by increasing $\mathrm{NO}_{2}$ levels in the northwest of the JISCO and the YWF (Fig. 3c). The maximum $\mathrm{NO}_{2}$ levels were observed in the wind farm between 20:00 to 23:00 UTC. Along with the change in wind direction from southeast to northeast at 04:00 UTC, 20 November, $\mathrm{NO}_{2}$ concentrations declined considerably compared to 20:00 UTC, 19 November (Fig. 3d). Accordingly, Fig. 4 illustrates the vertical cross section of hourly $\mathrm{NO}_{2}$ concentrations predicted by the control scenario run from 19:00 to 22:00 UTC, 19 November, along the transect across the fine domain (d03), highlighted by the red arrow line in Fig. 2. At 19:00 UTC, the $\mathrm{NO}_{2}$ plume extended from 0 to $25 \mathrm{~km}$ and moved from southeast to northwest along the transect of YWF (Fig. 2). Relatively lower concentrations can be identified near the upwind interface of YWF (5-7 km, Fig. 4a), in line with of the pollutants moved towards the northwest. By the next $2 \mathrm{~h}$ at 21:00 and 22:00 UTC, the plume had moved to the upwind border of YWF (Fig. 4c, d), and remained there. The levels of $\mathrm{NO}_{2}$ slightly increased from 19:00 UTC (Fig. 4b, c). The results are in line with the

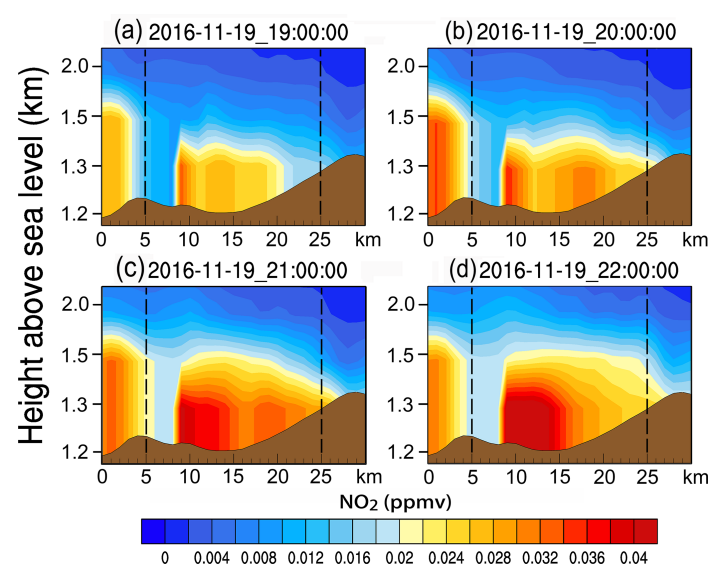

Figure 4. Vertical cross section of hourly $\mathrm{NO}_{2}$ concentration on the transect across the fine domain (d03) simulated by the control run (S1) at 19:00, 20:00, 21:00, and 22:00 UTC on 19 November. The transect is highlighted by the red arrow line in Fig. 2. Terrain height is shown by brown shading, and the $x$ axis indicates the length of the transect $(\mathrm{km})$ across the fine model domain $\mathrm{d} 03$ and YWF, bounded by black dashed line, extending from 5 to $25 \mathrm{~km}$.

horizontal advance of $\mathrm{NO}_{2}$ concentrations near the surface, as shown in Fig. 3c.

\section{2 $\mathrm{NO}_{2}$ in $\mathrm{YWF}$ due to roughness changes}

Using the wind farm roughness length parameterization $\left(z_{0}=1.51 \mathrm{~m}\right)$, we performed the second model scenario run. Figure 5 shows the modeled hourly $\mathrm{NO}_{2}$ concentrations at the same time as indicated in Fig. 3. Compared to the results from the control run, similar spatial patterns of $\mathrm{NO}_{2}$ from the model scenarios 1 and 2 can be observed, characterized by northwest transport of $\mathrm{NO}_{2}$ towards the YWF from its major industrial source to the southeast of YWF. However, the second model scenario run accounting for the roughness changes forced by the wind turbine setup appeared to yield higher $\mathrm{NO}_{2}$ concentrations. Considering that the atmospheric transport often dominates the spatial distribution of $\mathrm{NO}_{2}$ under prevailing winds, to identify the influence of the wind farm on $\mathrm{NO}_{2}$ air concentrations, we simply estimated the concentration differences between the two model scenarios including and excluding the wind farm. Figure 6 illustrates the differences of $\mathrm{NO}_{2}$ concentrations between the two model scenarios runs ( $\mathrm{S} 2$ minus $\mathrm{S} 1$ ). As shown, the positive concentration differences indicating higher concentrations from the S2 model run were found in the upwind and border region of the YWF and negative differences manifesting lower concentrations were identified within the YWF, particularly at 12:00 and 20:00 UTC. The mean positive concentration difference in the upwind region of the YWF is 0.009 ppmv. The estimated fraction $\left(C_{\mathrm{s} 2}-C_{\mathrm{s} 1}\right) / C_{\mathrm{s} 1} \times 100 \%$, where $C_{\mathrm{s} 1}$ and $C_{\mathrm{s} 2}$ are mean concentrations from the $\mathrm{S} 1$ and $\mathrm{S} 2$, is $23 \%$. The negative concentration difference within the 
(a) level1 2016-11-19 06:00:00

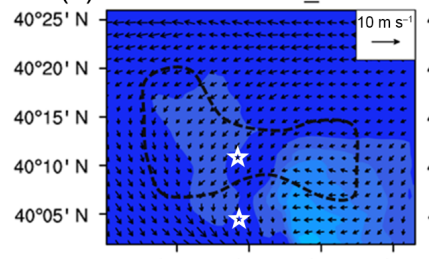

$96^{\circ} 50^{\prime}$ E $97^{\circ} 00^{\prime}$ E $97^{\circ} 10^{\prime}$ E $97^{\circ} 20^{\prime}$
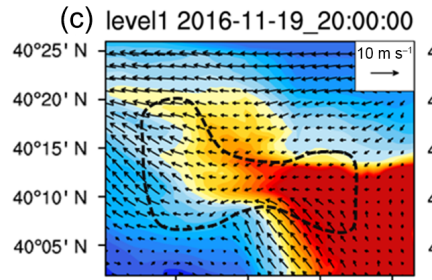

$96^{\circ} 50^{\prime}$ E $97^{\circ} 00^{\prime}$ E $97^{\circ} 10^{\prime}$ E $97^{\circ} 20^{\prime} \mathrm{E}$ $\mathrm{NO}_{2}$ (ppmv)

(b) level1 2016-11-19_12:00:00

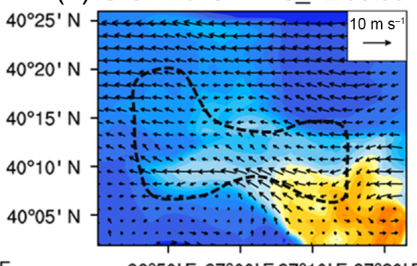

$96^{\circ} 50^{\prime} \mathrm{E} 97^{\circ} 00^{\prime} \mathrm{E} 97^{\circ} 10^{\prime} \mathrm{E} 97^{\circ} 20^{\prime} \mathrm{E}$ (d) level1 2016-11-20_04:00:00

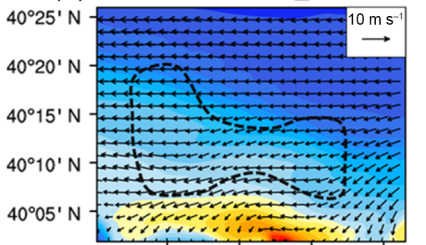

$96^{\circ} 50^{\prime} \mathrm{E} 97^{\circ} 00^{\prime} \mathrm{E} 97^{\circ} 10^{\prime} \mathrm{E} 97^{\circ} 20^{\prime} \mathrm{E}$ )

$\begin{array}{lllllllllll}0 & 0.004 & 0.008 & 0.012 & 0.016 & 0.02 & 0.024 & 0.028 & 0.032 & 0.036 & 0.04\end{array}$

Figure 5. Same as Fig. 3 but for the roughness change parameterization (S2) using the roughness length parameterization. The white star stands for the model grids within the wind farm $(44,52)$ and outside the wind farm $(44,48)$ for subsequent discussions (Fig. 9).

YWF is -0.009 ppmv, and the ratio of the mean concentration from $\mathrm{S} 2$ to that from the control run (S1) is $-33 \%$. These results suggest that the wind farm parameterized by the aerodynamic roughness change resulted in lower concentrations within the wind farm and higher concentrations in the upstream region.

The vertical cross section of hourly $\mathrm{NO}_{2}$ concentrations, simulated by S2 model run, from 19:00 to 22:00 UTC, 19 November, along the transect in the fine domain d03 (Fig. 2) is shown in Fig. 7. Although the maximum concentrations simulated by the S2 run were lower than that from the control run (S1), particularly within the wind farm, the plumes from the $\mathrm{S} 2$ run expanded to the upwind locations of the YWF. This can be seen from the $\mathrm{NO}_{2}$ vertical cross sections at 20:00, 21:00, and 22:00 UTC on 19 November (Fig. 7b-d) which show plume extension from 0 to $20 \mathrm{~km}$ compared to the modeled $\mathrm{NO}_{2}$ plumes in the control run. This is particularly evidenced at 20:00 and 21:00 UTC, agreeing with the horizontal distribution of $\mathrm{NO}_{2}$ near the surface (Fig. 6). Figure 8 shows the differences of modeled cross sections of $\mathrm{NO}_{2}$ concentrations between the first and second model scenario runs ( $\mathrm{S} 2$ minus $\mathrm{S} 1$ ). In general, higher $\mathrm{NO}_{2}$ concentration differences simulated from the $\mathrm{S} 2$ run can be observed at the upwind and interface of the extended YWF, especially at $0-9 \mathrm{~km}$ locations. Lower $\mathrm{NO}_{2}$ differences were observed within the YWF and its downstream region, manifesting again the influences of the wind farm on the spatial distribution of $\mathrm{NO}_{2}$ concentration. The negative differences became more obvious at 21:00 and 22:00 UTC. This likely resulted from stronger easterly and southeasterly wind after (a) level1 2016-11-19 06:00:00

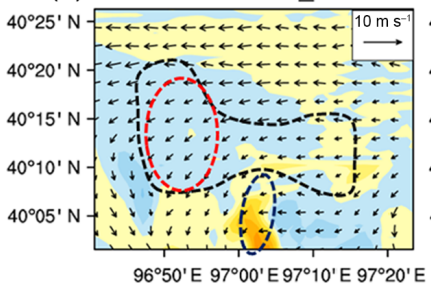

(c) level1 2016-11-19 20:00:00

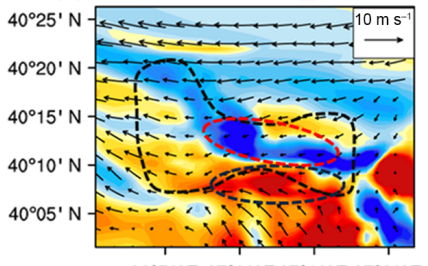

$96^{\circ} 50^{\prime}$ E $97^{\circ} 00^{\prime}$ E $97^{\circ} 10^{\prime}$ E $97^{\circ} 20^{\prime} \mathrm{E}$ $\triangle \mathrm{NO}_{2}(\mathrm{ppmv})$

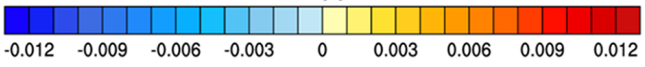

(b) level1 2016-11-19_12:00:00

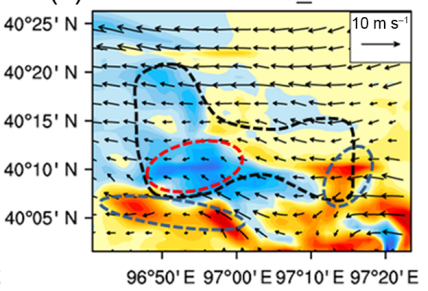

(d) level1 2016-11-20 04:00:00

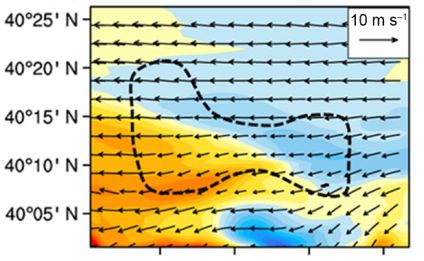

$96^{\circ} 50^{\prime}$ E $97^{\circ} 00^{\prime}$ E $97^{\circ} 10^{\prime}$ E $97^{\circ} 20^{\prime}$ E

Figure 6. Differences of modeled $\mathrm{NO}_{2}$ concentrations (ppmv) between S2 model run and control run (S1) at 06:00, 12:00, and 20:00 UTC on 19 November and 04:00 UTC on 20 November. The wind field is the same as that shown in Fig. 3, and YWF is encircled by black dashed line. The differences were calculated by $\mathrm{S} 2-\mathrm{S} 1$. The deep blue and red dashed lines encircled relatively higher and lower values of the concentration differences.

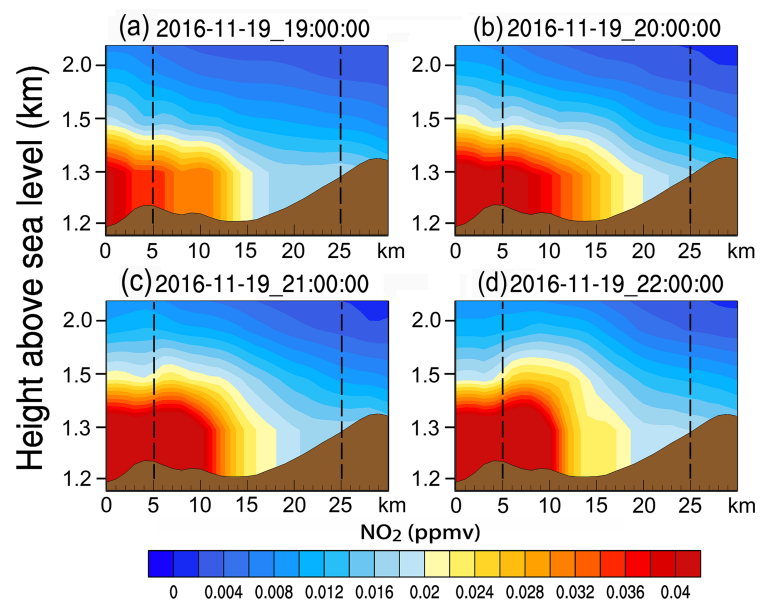

Figure 7. Same as Fig. 4 but for S2 model run using the roughness change parameterization scheme. The wind farm is bounded by black dashed line.

20:00 UTC (Fig. 3) which speeds up the atmospheric transport of $\mathrm{NO}_{2}$ from the upstream region to the wind farm.

Figure 9 shows vertical profiles of $\mathrm{NO}_{2}$ from the surface to the $1000 \mathrm{~m}$ height, simulated from the control run (S1) and S2 run respectively at the wind farm grid $(44,52)$ at 21:00 UTC, 19 November (Fig. 9a), and the upwind grid (44, 48) at 22:00 UTC, 19 November (Fig. 9b), which is $5 \mathrm{~km}$ away from the YWF marked by white star in Fig. 5a. Within the YWF (Fig. 9a), the S2 model scenario yielded consid- 


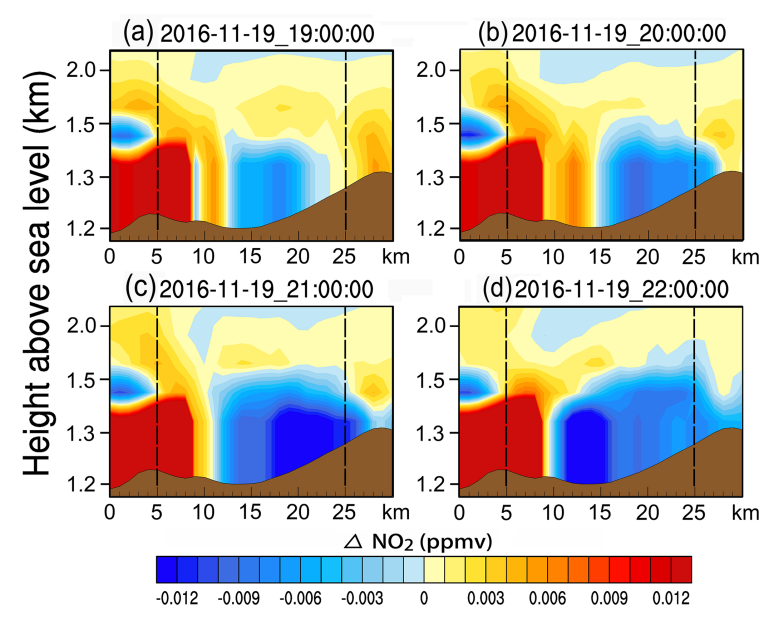

Figure 8. Cross section of the difference of modeled $\mathrm{NO}_{2}$ air concentrations between $\mathrm{S} 1$ and S2 model runs $(\mathrm{S} 2-\mathrm{S} 1)$ at 19:00, 20:00, 21:00, and 22:00 UTC, 19 November 2016, along a transect across YWF, as shown by the red arrow line in Fig. 2.

erably lower concentration (red dash line) below the wind turbine rotor height $(\sim 50 \mathrm{~m})$ and higher concentration from this level to the $600 \mathrm{~m}$ height compared to that of the control run (solid blue line). The modeled $\mathrm{NO}_{2}$ concentrations from the $\mathrm{S} 2$ run were lower by up to $23 \%$ than the $\mathrm{NO}_{2}$ level simulated from the control run. At the upstream site (Fig. 9b), the S2 run simulated higher $\mathrm{NO}_{2}$ concentration almost throughout the atmospheric boundary layer with the concentration level increasing by as much as $20 \%$ near the surface and up to $64 \%$ at the height of $130 \mathrm{~m}$ compared to the result from the control run. These results are in line with the $\mathrm{NO}_{2}$ horizontal distributions and cross sections obtained from the two model scenario runs.

\section{3 $\mathrm{NO}_{2}$ in $\mathrm{YWF}$ by wind turbine drag force parameterization}

To confirm the modeling results from the roughness change parameterization for the wind farm, we replaced this parameterization scheme with the wind turbine drag force parameterization (Eqs. 2-5). This scheme requires the input of the wind turbine density subject to the layout of wind turbines. We set the distance between wind turbines as $500 \mathrm{~m}$ in model scenario 3 (S3), and in the subsequent numerical scenario run (S4) this distance was extended to $1000 \mathrm{~m}$.

Figure 10 shows the differences of hourly $\mathrm{NO}_{2}$ concentrations at 06:00, 12:00, and 20:00 UTC on 19 November and 04:00 UTC on 20 November at the first eta level between $\mathrm{S} 3$ and S1 (S3 minus S1) on the same day. Again the $\mathrm{NO}_{2}$ concentrations within the YWF which were simulated by the wind turbine drag force parameterization scheme were lower than that from the control run (S1). The modeled mean concentration within the YWF by S3 was about $21 \%$ lower than that from the control run at 20:00 UTC. Mean concentrations at the upwind locations outside the YWF were $13 \%$ higher than that simulated by $\mathrm{S} 1$ model scenario. Overall, the values of the concentration differences between the S3 and S1 model scenarios were smaller than the differences between S2 and S1. Higher concentrations were found in the south and southeast of the YWF, differing somewhat from the result of S2, as shown in Fig. 6.

The vertical profiles of modeled $\mathrm{NO}_{2}$ concentrations at the two model grids within $(44,52)$ and at the upwind site $(50,48)$ marked in Fig. 3a from S3 and S1 are illustrated in Fig. 11. Lower concentrations at the wind farm grid extending from the surface to the $75 \mathrm{~m}$ height were predicted by $\mathrm{S} 3$ run with the strongest decline of $8 \%$ compared to $\mathrm{S} 1$ control run (Fig. 11a). Above this height, higher $\mathrm{NO}_{2}$ levels extended up to the $200 \mathrm{~m}$ height. At the upwind site, the S3 model run also predicted significantly higher $\mathrm{NO}_{2}$ concentration than that of S1, analogous to the result obtained by using the roughness length parameterization scheme (Fig. 9b). The maximum concentration in the vertical is about $27 \%$ higher than that from the control run.

We further adopted a low density layout of wind turbines by increasing the distance between two wind turbines from 500 to $1000 \mathrm{~m}$ (the fourth model scenario, S4) and rerun the WRF-Chem with the same model setups and configurations. Figure 12 shows $\mathrm{NO}_{2}$ concentration differences between $\mathrm{S} 4$ and S1 at 06:00, 12:00, and 20:00 UTC on 19 November and 04:00 UTC on 20 November, respectively. As seen, the spatial pattern of the concentration differences subject to the lower density wind turbine setup ( $1000 \mathrm{~m}$ distance) is almost identical to that from the higher density setup $(500 \mathrm{~m}$ distance). However, the mean $\mathrm{NO}_{2}$ concentration from $\mathrm{S} 4$ averaged over a region in the YWF, encircled by the red dashed line, was about $16 \%$ lower than that from the control run, showing a weaker influence on the changes in $\mathrm{NO}_{2}$ concentration, as compared to the $21 \%$ decrease in the higher wind turbine density setup (500 m spacing) from S3 run. At the upwind region of the YWF encircled by the blue dashed line (Fig. 11), the mean $\mathrm{NO}_{2}$ concentration from the lower wind turbine density run (S4) was the same as that from the higher density turbine setup (S3), both showing $13 \%$ increase in the mean $\mathrm{NO}_{2}$ concentrations from the control run (S1) compared to $\mathrm{S} 3$ and $\mathrm{S} 4$ models. This is expected because the wind turbine setup is not applicable outside of the wind farm.

The vertical profiles of $\mathrm{NO}_{2}$ concentrations from the lowest model vertical level above the surface to the $1000 \mathrm{~m}$ height at the model grid $(44,52)$ within the YWF and grid $(50,48)$ at the upwind site of the YWF from S4 and S1 model runs are illustrated in Fig. 13. Compared to the concentration profiles as shown in Fig. 11, the lower wind turbine setup does not markedly reduce the $\mathrm{NO}_{2}$ concentrations within the YWF. The S4 model predicted merely a $4 \%$ decline from the control run near the surface (Fig. 13a). This scenario also yielded less significant increase in the $\mathrm{NO}_{2}$ concentration at the upwind site of the YWF than that from the higher density turbine setup run with the maximum concentration increase 

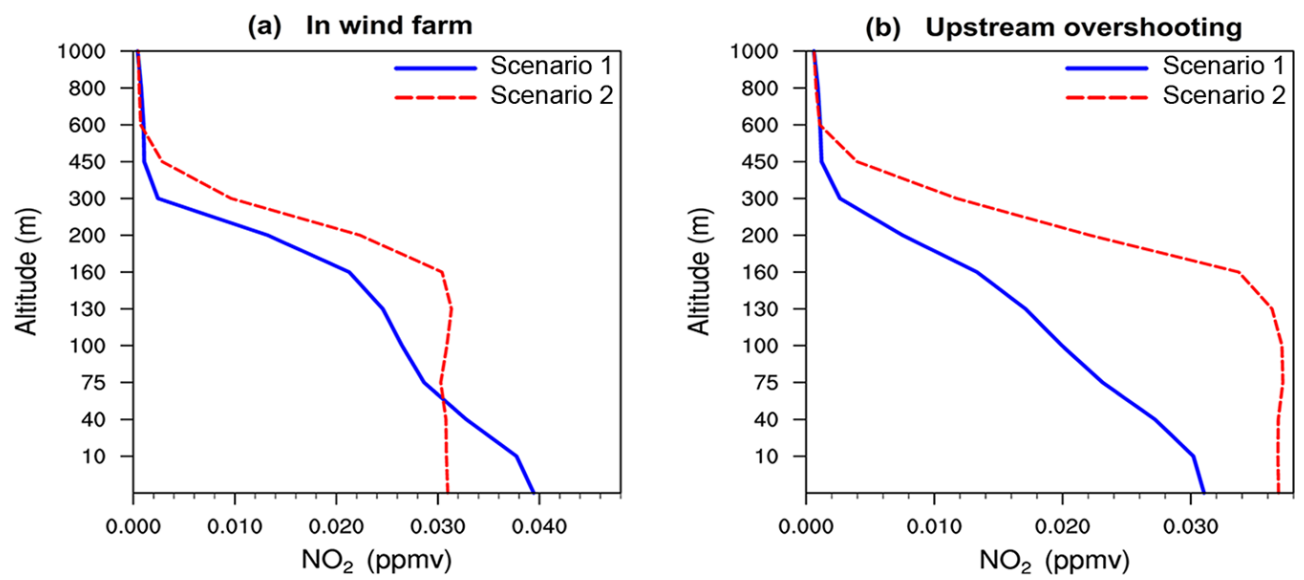

Figure 9. Vertical profiles of $\mathrm{NO}_{2}$ concentrations at two model grids at (a) $(44,52)$ at 21:00 UTC on 19 November within the YWF and (b) $(44,48)$ at 22:00 UTC on 19 November in the upstream of the YWF, simulated by the control run (S1, blue solid line) and S2 run accounting for the roughness changes in the wind farm (red dashed line).

(a) level1 2016-11-19_06:00:00

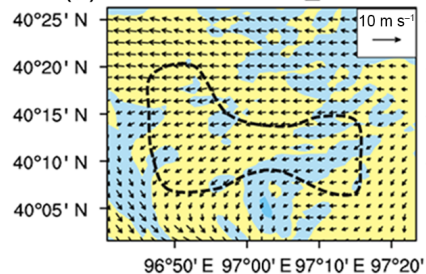

(c) level1 2016-11-19_20:00:00

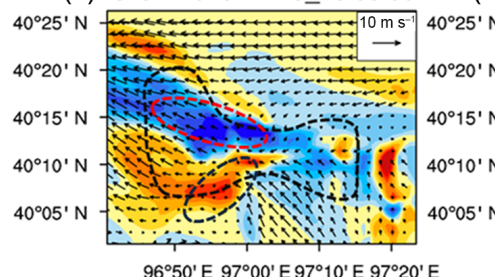

$96^{\circ} 50^{\prime}$ E $97^{\circ} 00^{\prime}$ E $97^{\circ} 10^{\prime}$ E $97^{\circ} 20^{\prime} \mathrm{E}$

$\triangle \mathrm{NO}_{2}(\mathrm{ppmv})$

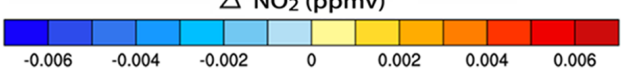

Figure 10. Same as Fig. 6 but for the concentration differences $\Delta C$ between $\mathrm{S} 3$ model run and the control run $(\mathrm{S} 1)$, given by $\mathrm{S} 3-\mathrm{S} 1$.

by $20 \%$ from the control run, compared with the $27 \%$ increase in the higher turbine density simulation (S3).

\section{Discussions}

In this numerical case study, the Yumen-Guazhou wind farm, the world largest wind farm located in the western Hexi Corridor, China, was parameterized by the wind turbineinduced roughness change scheme and wind turbine drag force scheme, to assess the potential influences of the wind farm on spatial distribution of $\mathrm{NO}_{2}$ within and around the wind farm. Overall, by making use of these two parameterization schemes, our modeling results predicted higher $\mathrm{NO}_{2}$ concentrations at the immediate upstream and border regions of the YWF and lower concentrations within the YWF. As previously mentioned, a wind farm acts to increase the aerodynamic roughness lengths through two mechanisms. First, the layout and array of wind turbines throughout the wind farm alter underlying surface characteristics (roughness elements) enhancing the roughness lengths within the wind farm. Second, because wind turbines take out momentum proportional to the wind speed, the mean wind speed will be reduced relative to the ambient wind in the wind farm (Emeis and Frandsen, 1993). From the well-known logarithmic wind law for neutral conditions in the surface boundary layer $(\sim 100 \mathrm{~m})$, the reduction of wind speed implies increasing aerodynamic roughness length (Ma and Daggupaty, 2000). As a result, an internal boundary layer (IBL) may develop in which the flow characteristics only depend on the new surface roughness. Outside the IBL the flow is identical to the upwind flow (Garratt, 1994; Frandsen, 2007). Hence, the presence of the IBL leads to a step change in the roughness length in the interface between rough (in the wind farm) and smooth (outside the wind farm) surfaces. Thus, the IBL is particularly evident in the upwind interface. For an air pollutant coming from the upstream of the wind farm on land, the step change in the roughness from the smooth upstream surface to the rough surface over the wind farm could result in an "overshooting" of the surface stress in the wind farm (Garratt, 1994), slowing down the concentration transport by wind. This would lead to the accumulation of the air pollutants featured by a step change in the concentration at the "edge" (interface) of the wind farm. For the pollutant out of the wind farm to the downstream region, the roughness changes from rough to smooth surface are expected to cause an "undershooting" of the downstream stress which accelerates the pollutant transport in the downwind edge of the wind farm. 
(a) In wind farm

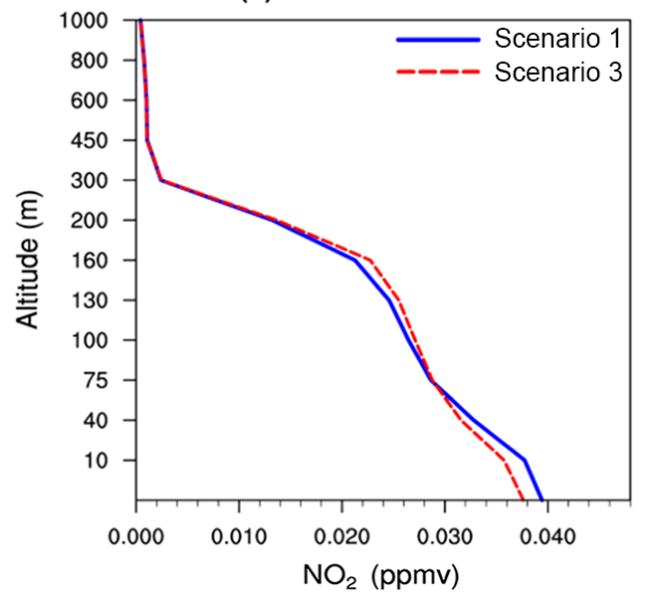

(b) Upstream overshooting

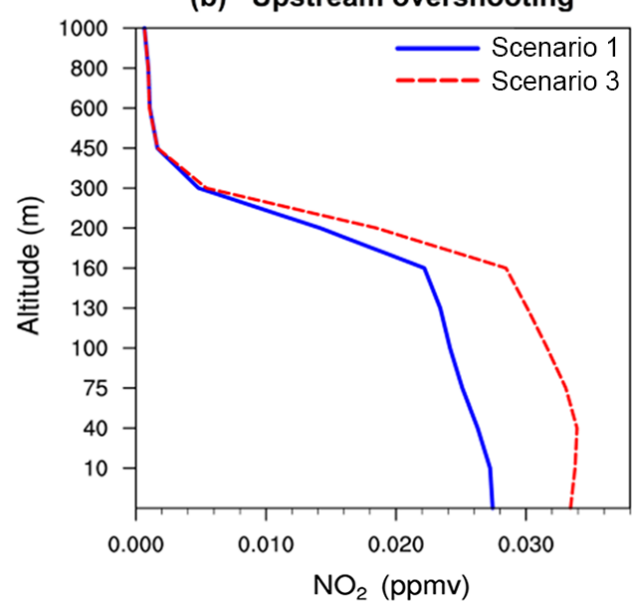

Figure 11. Vertical profiles of $\mathrm{NO}_{2}$ concentration from the surface to the $1000 \mathrm{~m}$ height from the control run ( $\mathrm{S} 1$, solid blue line) and $\mathrm{S} 3$ run (red dashed line) at (a) the YWF grid $(44,52)$ at 21:00 UTC on 19 November, and (b) the upwind grid $(50,48)$ at $22: 00$ UTC on 19 November.

(a) level1 2016-11-19 06:00:00

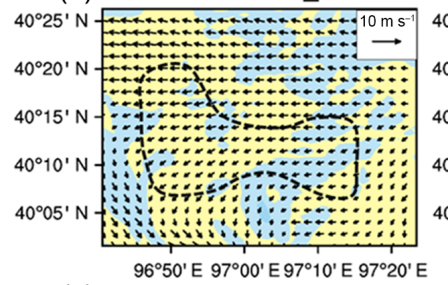

(c) level1 2016-11-19_20:00:00

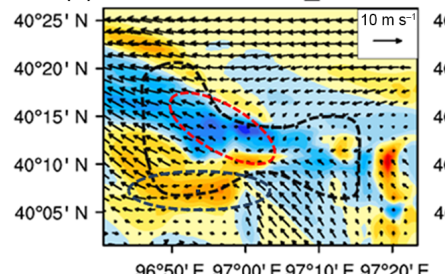

$96^{\circ} 50^{\prime}$ E $97^{\circ} 00^{\prime}$ E $97^{\circ} 10^{\prime}$ E $97^{\circ} 20^{\prime}$ E $\triangle \mathrm{NO}_{2}(\mathrm{ppmv})$

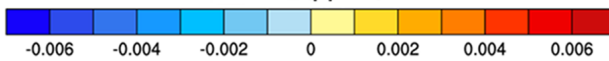

Figure 12. Same as Fig. 6 but for concentration differences between $\mathrm{S} 4$ run and the control run (S1), given by $\mathrm{S} 4-\mathrm{S} 1$.

Figure 14 is a schematic view of the IBL and the edge effect on an air pollutant passing through a wind farm induced by the mechanic internal boundary layer. In the figure, $h_{\mathrm{i}}$ is the top of IBL, and $h_{\mathrm{ss}}$ is a sublayer below $h_{\mathrm{i}}$ in which the wind (momentum) has to be adjusted to accommodate the new underlying surface. When the air flow moves from a relatively smooth to rough surface, the wind speed in the IBL will decrease (Garratt, 1994; Bradley, 1968; Elliot, 1958). This deceleration of wind speed results in the accumulation of air pollution (overshooting), characterized by increasing air concentration in the immediate upwind of the wind farm.

We developed a simple model in the neutral surface boundary layer to address the changes in the concentration of an air pollutant induced by the roughness changes in a wind farm, given by

$\Delta c=-\frac{F_{\mathrm{c}}}{\kappa u_{\mathrm{h}}\left(c_{D_{\mathrm{eff}}}\right)^{\frac{1}{2}}} \ln \left(\frac{z}{z_{0 \mathrm{c}-\mathrm{eff}}}\right)$,

where $\Delta c=c-c_{0}$, which is the gradient of air concentration of a pollutant at $z_{0 \mathrm{c} \text {-eff }}$ and $z$ height in the wind farm, $F_{\mathrm{c}}\left(\mu \mathrm{g} \mathrm{m}^{-2} \mathrm{~s}^{-1}\right)$ is a diffusive concentration flux $\left(=\overline{w^{\prime} c^{\prime}}=\right.$ $\left.u_{*} c_{*}\right)$, where $u_{*}$ is the fraction velocity $\left(\mathrm{m} \mathrm{s}^{-1}\right)$, and $c_{*}$ is a turbulent scale for concentration $\left(\mu \mathrm{g} \mathrm{m}^{-3}\right) \cdot u_{\mathrm{h}}$ is the wind speed $\left(\mathrm{m} \mathrm{s}^{-1}\right)$ at the hub height of the wind farm, $c_{D_{\text {eff }}}$ is an effective drag coefficient by summing the surface drag coefficient within the wind farm and the averaged wind turbine drag coefficient, $\kappa$ is the von Kármán constant $(=0.4), z$ is the height $(0-100 \mathrm{~m})$, and $z_{0 \mathrm{c} \text {-eff }}$ is an effective roughness length $(\mathrm{m})$ for concentration, defined by

$z_{0 \text { c-eff }}=0.1 z \exp \left(-\frac{\kappa}{\left\{\left[\frac{\kappa}{\left(\ln \left(z_{00} / h_{\mathrm{b}}\right)\right)}\right]^{2}-c_{\mathrm{t}}\right\}^{\frac{1}{2}}}\right)$,

where $z_{00}$ is an apparent roughness length, $h_{\mathrm{b}}$ is the hub height, and $c_{\mathrm{t}}$ is the averaged wind turbine drag coefficient. Figure 15 displays the vertical profiles of the concentration gradient in the neutral surface boundary layer $(0-100 \mathrm{~m})$ within and outside the wind farm. Considerably smaller concentration gradient can be seen within the wind farm compared to that outside the wind farm, forced by increasing drag force under the rough underlying surface in the wind farm.

An interesting feature in the vertical profiles of the simulated $\mathrm{NO}_{2}$ air concentrations in the presence of the YWF by the two parameterization schemes (Figs. 9a, 11a, and $13 \mathrm{a})$ is the lower $\mathrm{NO}_{2}$ level below the hub height $(0-70 \mathrm{~m})$ 
(a) In wind farm

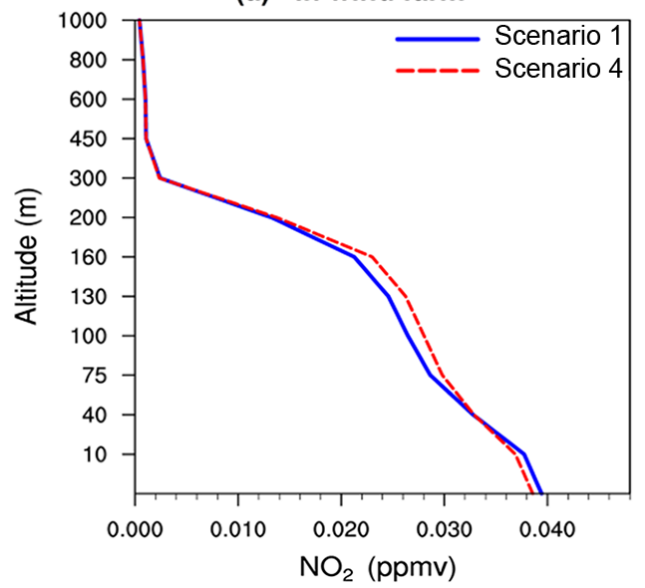

(b) Upstream overshooting

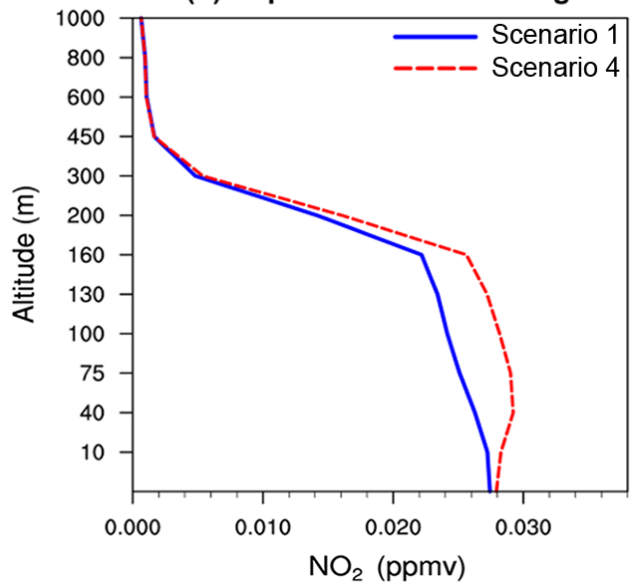

Figure 13. Vertical profiles of $\mathrm{NO}_{2}$ concentration from the first vertical model level above the surface to the $1000 \mathrm{~m}$ height from the control run ( $\mathrm{S} 1$, solid blue line) and S4 run (red dashed line) at (a) the YWF grid $(44,52)$ at 21:00 UTC on 19 November, and (b) the upwind grid $(50,48)$ at 22:00 UTC on 19 November.

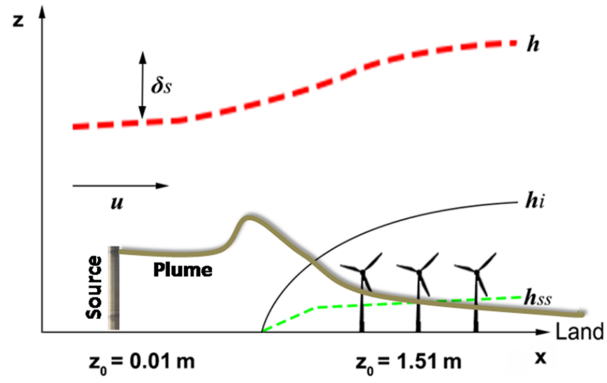

Figure 14. Schematic view of the IBL and an air pollutant passing through a wind farm. The IBL and PBL change from smaller roughness length $0.01 \mathrm{~m}$ to large roughness length $1.51 \mathrm{~m}$. The red dashed line $h$ indicates the PBL thickness, black solid line $h_{\mathrm{i}}$ indicates the IBL, the green dashed line $h_{\mathrm{Ss}}$ indicates a sublayer, $\boldsymbol{u}$ indicates the wind vector, and $\delta_{\mathrm{s}}$ indicates the upward displacement of PBL thickness change.

and the higher level above the hub height compared with $\mathrm{NO}_{2}$ concentration simulated by the control run (the YWF was not taken into consideration). It has been reported that wind farms could significantly slow down the wind speed at the turbine hub height level and the turbulence generated by wind turbine rotors create eddies which enhance vertical mixing of momentum and scalars (Baiyda et al., 2004). As a result, there may be a wind speed deficit in the neutral boundary layer. The modeled $\mathrm{NO}_{2}$ concentration profiles in the YWF as shown in Figs. 9a, 11a, and 13a are likely associated with the vertical mixing of air concentrations. Nevertheless, the magnitude of the air concentration deficit in the neutral boundary layer within the wind farm simulated in this model investigation depends on wind farm parameterization. The roughness change parameterization yielded the largest concentration deficit, whereas the turbine drag force parame-

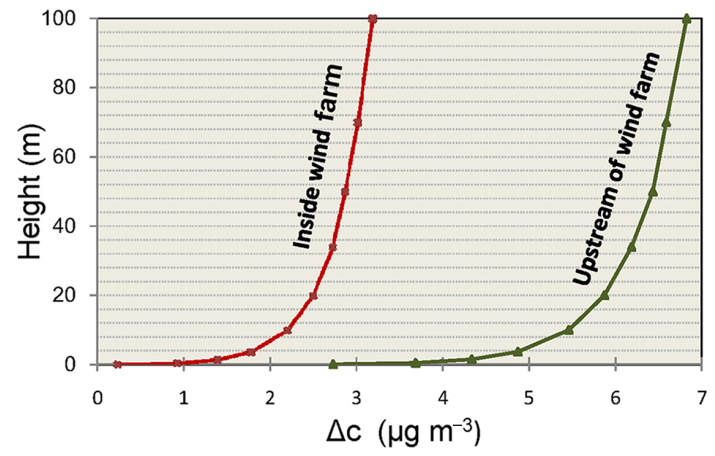

Figure 15. Vertical profile of concentration gradient in the neutral boundary layer. The wind speed at the hub height was set as $4 \mathrm{~m} \mathrm{~s}^{-1}$, the surface roughness length was set as $0.01 \mathrm{~m}$, and hub height as $60 \mathrm{~m}$. Concentrations were taken as $100 \mu \mathrm{g} \mathrm{m}^{-3}$ at the $1.5 \mathrm{~m}$ height and $80 \mu \mathrm{g} \mathrm{m}^{-3}$ at the $10 \mathrm{~m}$ height.

terization with the low wind turbine density produced a moderate deficit. In the immediate upwind region of the YWF, the two parameterization schemes all predicted notably higher concentrations in the vertical up to $450-600 \mathrm{~m}$ height, manifesting significant "edge effect" and the overshooting signature. We wish to point out that here we only discuss the wind profiles over the wind farm in the neutral boundary layer. The diurnal changes in $\mathrm{NO}_{2}$ concentrations presented in the last section took place in the stratified (non-neutral) atmosphere. However, since the wind profiles in the stable and unstable boundary layer can be treated as a departure from the neutral condition, our interpretations for the "edge effect" should hold for the non-neutral conditions.

It is worthwhile to note that the identification of the "edge effect" or overshooting in the immediate upwind and the undershooting in the downwind region of the wind farm 
largely depends on the proper location of upstream emission sources and downstream wind farm which should be aligned with the wind direction. Figure S5 displays the wind field from the control run and the differences $(\Delta \mathrm{V})$ between the perturbed wind fields by the wind farm parameterizations (Fig. S5b-d) and the wind field from the control run (Fig. S5a) at 20:00 UTC on 19 November at the fourth model level $(\sim 100 \mathrm{~m})$. This vertical level is the nearest level to the hub height (70-93 m). At this level, the wind speed should exhibit largest reduction within the wind farm (Emeis, 2010; Frandsen, 2007; Barrie and Kirk-Davidoff, 2010). As shown, the background wind field in the model domain simulated by the control run (model scenario 1) generated easterly and southeasterly winds across the fine model domain (d03) with stronger easterly winds in the north, except for those model grids near the south boundary of the domain where westerly wind prevailed. Analogous to the previous findings (Fitch et al., 2012), all three wind farm parameterization schemes yield lower wind speed, as shown by $-\Delta V$ across the YWF, particularly in the roughness change parameterization scheme. Outside the YWF, the wind turbine parameterization yielded very small $\Delta V$ (Fig. S5c, d). The roughness change parameterization also predicted $-\Delta V$ across the YWF but positive $\Delta \mathrm{V}$ on the south and north lateral boundaries. This feature has also been simulated by Fitch et al. (2012). Figure S3 illustrates the modeled TKE overlapped with vector winds at 20:00 UTC on 19 November at the fourth model level $(\sim 100 \mathrm{~m})$. All three wind farm parameterization schemes predicted largest TKE in the northwestern YWF (Fig. S6b-d) as compared to non-wind farm (control run) simulations in which no significantly higher TKE was observed (Fig. S6a), corresponding nicely to the largest wind speed deficit and concentration reduction (Figs. 6 and 9). The result is also in line with the TKE field in a relatively smaller wind farm reported by Fitch et al. (2012).

It is also noted that if a large-scale wind farm could disturb atmospheric dispersion of an air pollutant and is located near a city, it may influence the spatiotemporal distribution of the pollutant over the city. This would depend on how far the influence of the edge effect could be extended to the surrounding region of a large-scale wind farm. The edge effect of an internal boundary layer can be estimated via a "fetchheight ratio" (Garratt, 1994). In micro-meteorology, such a ratio is typically about $1: 100$ from the rough to smooth surface. In the smooth-to-rough surface case, the fetch-height ratio is approximately 2 times greater than that in the rough to smooth case (Garratt, 1994). This suggests that if the mean obstacle height of the YWF is equivalent to the wind turbine hub height $(\sim 100 \mathrm{~m})$, the fetch over which the edge effect could be extended would be $10 \mathrm{~km}$. If the westerly wind prevails in winter, and knowing that the roughness changes from rough to smooth surface would accelerate the pollutant transport in the downwind edge of the wind farm, we would expect that the eastward transport of air pollutants might influence downwind residential areas, such as Jiuquan and Ji- ayuguan City in our case (Fig. 1b), located in the downstream of the YWF. However, given that there were no significant emission sources in the upstream of the YWF under the westerly wind regime, the edge effect on the air quality in these two largest cities in the Hexi Corridor was negligible.

\section{Conclusions}

Extensive model simulations in a case study were carried out to quantify the influence of the world largest wind farm on the spatial distribution of $\mathrm{NO}_{2}$ within and around this wind farm. In this case study, $\mathrm{NO}_{2}$ was emitted from a largescale iron and steel plant (JISCO) located $110 \mathrm{~km}$ southeast of the Yumen wind farm (YWF). Under prevailing easterly and southeasterly winds, $\mathrm{NO}_{2}$ concentrations were conveyed from the JISCO to the YWF. Four model scenarios were set up to examine the differences among the modeled $\mathrm{NO}_{2}$ air concentrations with and without the presence of the YWF. In the four model scenario investigations, we implemented two approaches to parameterize the YWF, the roughness length, and wind turbine drag force schemes into the WRF-Chem model. We then compared the differences of modeled $\mathrm{NO}_{2}$ concentrations and concentration cross sections and vertical profiles within the YWF and immediately upwind of the YWF. Overall, the modeling results showed relatively higher concentration at the immediate upwind region and the upwind border region of the YWF, and lower concentration within and the downwind region of the YWF, suggesting an "edge effect" of the wind farm on air pollutants passing over the wind farm. We posit that the development of the internal boundary layer due to roughness changes induced by the YWF plays a significant role to this edge effect.

We proposed that the fluctuations of air pollution over a wind farm might depend on the source locations and proximity, wind speed and direction, underlying surface characteristics, and wind turbine size and layout in the wind farm. This modeling study is the first investigation of the effect of a wind farm on air pollutants within and around a wind farm. Given the rapid development of wind energy worldwide, the increasing number of wind farms might potentially influence the atmospheric transport of air pollutants and air quality forecasting. More modeling assessments for the influence of wind farms on air pollution should be carried out to assess such potential influences.

Data availability. The HTAP_V2 anthropogenic emissions are publicly available from the Task Force on Hemispheric Transport of Air Pollution (http://www.htap.org/; Task Force on Hemispheric Transport of Air Pollution, 2012). The FNL reanalysis data provided by the National Centers for Environmental Prediction/National Center for Atmospheric Research (NCEP/NCAR) are available at https://rda.ucar.edu/datasets/ds083.3/index.html (NCEP/NCAR, 2015). The measured meteorology data of weather stations are from Climatic Data Center, National Meteorological 
Information Center, China Meteorological Administration (CMA), available at http://data.cma.cn/ (CMA, 2015).

\section{The Supplement related to this article is available online at https://doi.org/10.5194/acp-17-14239-2017- supplement.}

Competing interests. The authors declare that they have no conflict of interest.

Acknowledgements. This work is supported by the National Natural Science Foundation of China (grants 41503089, 41371478, and 41671460). We thank Zuohao Cao and Junhua Zhang of Environment and Climate Change Canada for the internal review of the manuscript.

Edited by: Qiang Zhang

Reviewed by: two anonymous referees

\section{References}

Baidya, R. S.: Simulating impacts of wind farms on local hydrometeorology, J. Wind Eng. Ind. Aerod., 99, 491-498, https://doi.org/10.1016/j.jweia.2010.12.013, 2011.

Baidya, R. S., Pacala, S. W., and Walko, R. L.: Can large wind farms affect local meteorology?, J. Geophys. Res., 109, D19101, https://doi.org/10.1029/2004JD004763, 2004.

Barrie, D. B. and Kirk-Davidoff, D. B.: Weather response to a large wind turbine array, Atmos. Chem. Phys., 10, 769-775, https://doi.org/10.5194/acp-10-769-2010, 2010.

Beljaars, A. C. M.: The parameterization of surface fluxes in largescale models under free convection, Q. J. Roy. Meteor. Soc., 121, 255-270, https://doi.org/10.1002/qj.49712152203, 1994.

Blahak, U., Goretzki, B., and Meis, J.: A simple parameterization of drag forces induced by large wind farms for numerical weather prediction models, in: Proceedings of European wind energy conference and exhibition, 1 June 2010, Warsaw, Poland, 4577-4585, available at: http://proceedings.ewea.org/ ewec2010/allfiles2/757_EWEC2010presentation.pdf (last access: 28 November 2017), 2010.

Bradley, E. F.: A micrometeorological study of velocity profiles and surface drag in the region modified by a change of surface roughness, Q. J. Roy. Meteor. Soc., 94, 361-379, https://doi.org/10.1002/qj.49709440111, 1968.

Chen, F. and Dudhia, J.: Coupling an advanced land surfacehydrology model with the Penn State-NCAR MM5 modeling system. Part I: Model implementation and sensitivity, Mon. Weather Rev., 129, 569-585, https://doi.org/10.1175/15200493(2001)129<0569:Caalsh>2.0.CO;2, 2001.

China Certified Emission Reduction (CCER) Platform: China Greenhouse Gas Voluntary Emission Reduction Project Monitoring Report (F-CCER-MR), available at: http: //cdm.cchina.gov.cn/zyDetail.aspx?newsId=58797\&TId=169 (last access: 28 November 2017), 2015 (in Chinese).
Climatic Data Center, National Meteorological Information Center, China Meteorological Administration (CMA): China Meteorological Observatory hour by hour observation data, available at: http://data.cma.cn/ (last access: 28 November 2017), 2015.

Elliott, W. P.: The growth of the atmospheric internal boundary layer, Eos T. Am. Geophys. Un., 39, 1048-1054, https://doi.org/10.1029/TR039i006p01048, 1958.

Emeis, S.: A simple analytical wind park model considering atmospheric stability, Wind Energy, 13, 459-469, https://doi.org/10.1002/we.367, 2010.

Emeis, S. and Frandsen, S.: Reduction of horizontal wind speed in a boundary layer with obstacles, Bound.-Lay. Meteorol., 64, 297 305, https://doi.org/10.1007/BF00708968, 1993.

Fast, J. D., Gustafson Jr., W. I., Easter, R. C., Zaveri, R. A., Barnard, J. C., Chapman, E. G., Grell, G. A., and Peckham, S. E.: Evolution of ozone, particulates, and aerosol direct radiative forcing in the vicinity of Houston using a fully coupled meteorology-chemistry-aerosol model, J. Geophys. Res., 111, D21305, https://doi.org/10.1029/2005JD006721, 2006.

Fitch, A. C., Olson, J. B., Lundquist, J. K., Dudhia, J., Gupta, A. K., Michalakes, J., and Barstad, I.: Local and Mesoscale Impacts of Wind Farms as Parameterized in a Mesoscale NWP Model, Mon. Weather Rev., 140, 3017-3038, https://doi.org/10.1175/MWRD-11-00352.1, 2012.

Frandsen, S.: On the wind speed reduction in the center of large clusters of wind turbines, J. Wind Eng. Ind. Aerod., 39, 251-265, https://doi.org/10.1016/0167-6105(92)90551-K, 1992.

Frandsen, S. T.: Turbulence and turbulence generated structural loading in wind turbine clusters, Riso-R-1188(EN), Forsknings center Risoe, Roskilde, Denmark, 2007.

Garratt, J. R.: Review: the atmospheric boundary layer, Earth-Sci. Rev., 37, 89-134, https://doi.org/10.1016/0012-8252(94)900264, 1994.

Grell, G. A. and Devenyi, D.: A generalized approach to parameterizing convection combining ensemble and data assimilation techniques, Geophys. Res. Lett., 29, 587-590, https://doi.org/10.1029/2002GL015311, 2002.

Grell, G. A., Peckham, S. E., Schmitz, R., McKeen, S. A., Frost, G., Skamarock, W. C., and Eder, B.: Fully coupled "online" chemistry in the WRF model, Atmos. Environ., 39, 6957-6976, https://doi.org/10.1016/j.atmosenv.2005.04.027, 2005.

Guenther, A. B., Jiang, X., Heald, C. L., Sakulyanontvittaya, T., Duhl, T., Emmons, L. K., and Wang, X.: The Model of Emissions of Gases and Aerosols from Nature version 2.1 (MEGAN2.1): an extended and updated framework for modeling biogenic emissions, Geosci. Model Dev., 5, 1471-1492, https://doi.org/10.5194/gmd-5-1471-2012, 2012.

GWEC (Global Wind Energy Council): Global wind report annual market update 2015, available at: http://www.gwec.net/ wp-content/uploads/vip/GWEC-Global-Wind-2015-Report_ April-2016_22_04.pdf, last access: 3 July 2016.

Hong, S. Y., Noh, Y., and Dudhia, J.: A new vertical diffusion package with an explicit treatment of entrainment processes, Mon. Weather Rev., 134, 2318-2341, https://doi.org/10.1175/MWR3199.1, 2006.

IEA (International Energy Agency): Technology Roadmap: China Wind Energy Development Roadmap 2050, available at: http://www.iea.org/publications/freepublications/publication/ 
technology-roadmap-china-wind-energy-developmentroadmap-2050.Nakanishi, M. and Niino, H.: Development of an improved turbuhtml (last access: 28 November 2017), 2011.

Keith, D. W., De Carolis, J. F., Denkenberger, D. C., Lenschow, D. H., Malyshev, S. L., Pacala, S., and Rasch, P. J.: The influence of large-scale wind power on global climate, P. Natl. Acad. Sci. USA, 101, 16115-16120, https://doi.org/10.1073/pnas.0406930101, 2004.

Kim, H. J. and Wang, B.: Sensitivity of the wrf model simulation of the east asian summer monsoon in 1993 to shortwave radiation scheme and ozone absorption, Asia-Pac. J. Atmos. Sci., 47, 167180, https://doi.org/10.1007/s13143-011-0006-y, 2011.

Lettau, H.: Note on Aerodynamic roughness-parameter estimation on the basis of roughness-element description, J. Appl. Meteorol., 8, 828-832, https://doi.org/10.1175/15200450(1969)008<0828:NOARPE>2.0.CO;2, 1965.

Lin, Y. L., Farley, R. D., and Orville, H. D.: Bulk parameterization of the snow field in a cloud model, J. Clim. Appl. Meteorol., 22, 1065-1092, https://doi.org/10.1175/15200450(1983)022<1065:BPOTSF>2.0.CO;2, 1983.

Loss, S. R., Will, T., and Marra, P. P.: Estimates of bird collision mortality at wind facilities in the contiguous United States, Biol. Conserv., 168, 201-209, https://doi.org/10.1016/j.biocon.2013.10.007, 2013.

Ma, J. and Daggupaty, S. M.: Using all observed information in a variational approach in measuring $\mathrm{z} 0 \mathrm{~m}$ and $\mathrm{z} 0 \mathrm{t}, \mathrm{J}$. Appl. Meteorol., 39, 1391-1401, https://doi.org/10.1175/15200450(2000)039<1391:UAOIIA>2.0.CO;2, 2000.

Magoha, P.: Footprints in the wind?: Environmental impacts of wind power development, Refocus, 3, 30-33, https://doi.org/10.1016/S1471-0846(02)80083-X, 2002.

Mellor, G. L. and Yamada, T.: A hierarchy of turbulence closure models for planetary boundary layers, J. Atmos. Sci., 31, 1791-1806, https://doi.org/10.1175/15200469(1974)031<1791:AHOTCM>2.0.CO;2, 1974.

Middleton, P., Stockwell, W. R., and Carter, W. P. L.: Aggregation and analysis of volatile organic compound emissions for regional modeling, Atmos. Environ. A-Gen., 24, 1107-1133, https://doi.org/10.1016/0960-1686(90)90077-Z, 1990.

Mlawer, E. J., Taubman, S. J., Brown, P. D., Iacono, M. J., and Clough, S. A.: Radiative transfer for inhomogeneous atmospheres: RRTM, a validated correlated-k model for the longwave, J. Geophys. Res-Atmos., 102, 16663-16682, https://doi.org/10.1029/97JD00237, 1997.

Model of Emissions of Gases and Aerosols from Nature: Civil and Environmental Engineering, Washington State University, available at: http://lar.wsu.edu/megan/ (last access: 28 November 2017), 2011. lence closure model for the atmospheric boundary layer, Meteorol. Soc. Jpn, 87, 895-912, https://doi.org/10.2151/jmsj.87.895, 2009.

National Centers for Environmental Prediction/National Center for Atmospheric Research (NCEP/NCAR): NCEP GDAS/FNL 0.25 Degree Global Tropospheric Analyses and Forecast Grids, available at: https://rda.ucar.edu/datasets/ds083.3/index.html (last access: 28 November 2017), 2015.

Oerlemans, S., Sijtsmaa, P., and Mendez, L. B.:Location and quantification of noise sources on a wind turbine, J. Sound Vib., 299, 869-883, https://doi.org/10.1016/j.jsv.2006.07.032, 2007.

Porté-Agel, F., Lu, H., and Wu, Y.: Interaction between large wind farms and the atmospheric boundary layer, Proc. Iutam, 10, 307318, https://doi.org/10.1016/j.piutam.2014.01.026, 2014.

Rooijmans, P.: Impact of a large-scale offshore windfarm on meteorology: Numerical simulations with a mesoscale circulation model, Utrecht University, Utrecht, the Netherlands, available at: https://docs.wind-watch.org/rooijmansmesoscale.pdf (last access: 28 November 2017), 2004.

Saidur, R., Rahim, N. A., Islam, M. R., and Solangi, K. H.: Environmental impact of wind energy, Renew. Sust. Energ. Rev. 15, 2423-2430, https://doi.org/10.1016/j.rser.2011.02.024, 2011.

Task Force on Hemispheric Transport of Air Pollution: HTAP harmonized emissions database 2008-2010, available at: http: //edgar.jrc.ec.europa.eu/htap_v2/index.php (last access: 3 July 2017), 2012.

Wang, C. and Prinn, R. G.: Potential climatic impacts and reliability of very large-scale wind farms, Atmos. Chem. Phys., 10, 20532061, https://doi.org/10.5194/acp-10-2053-2010, 2010.

Yarwood, G., Rao, S., Yocke, M., and Whitten, G.: Updates to the carbon bond chemical mechanism: CB05, Final report to the US EPA, RT-0400675, available at: http://www.camx.com/ (last access: 2 May 2017), 2005.

Zhang, Y. and Zhao, W.: Effects of variability in land surface characteristics on the summer radiation budget across desert-oasis region in northwestern china, Theor. Appl. Climatol., 119, 771780, https://doi.org/10.1007/s00704-014-1144-9, 2015.

Zhou, L., Tian, Y., Baidya, R. S., Thorncroft, C., Bosart, L. F., and $\mathrm{Hu}, \mathrm{Y}$.: Impacts of wind farms on land surface temperature, Nat. Clim. Change, 2, 539-543, https://doi.org/10.1038/nclimate1505, 2012. 